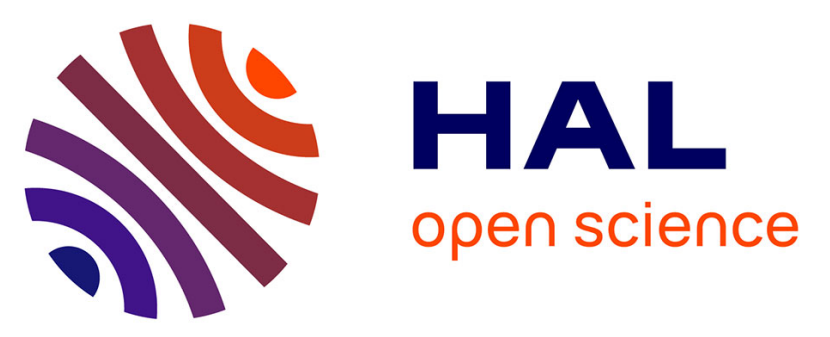

\title{
The alkyl chain length of 3-alkyl-3',4',5,7-tetrahydroxyflavones modulates effective inhibition of oxidative damage in biological systems: illustration with LDL, red blood cells and human skin keratinocytes
}

Paulo Filipe, Artur M.S. Silva, Raquel S.G.R. Seixas, Diana C.G.A. Pinto, Alvaro Santos, Larry K. Patterson, João N. Silva, José A.S. Cavaleiro, João P. Freitas, Jean-Claude Mazière, et al.

\section{To cite this version:}

Paulo Filipe, Artur M.S. Silva, Raquel S.G.R. Seixas, Diana C.G.A. Pinto, Alvaro Santos, et al.. The alkyl chain length of 3-alkyl-3',4',5,7-tetrahydroxyflavones modulates effective inhibition of oxidative damage in biological systems: illustration with LDL, red blood cells and human skin keratinocytes. Biochemical Pharmacology, 2009, 77 (6), pp.957. 10.1016/j.bcp.2008.11.023 . hal-00531845

\section{HAL Id: hal-00531845 \\ https://hal.science/hal-00531845}

Submitted on 4 Nov 2010

HAL is a multi-disciplinary open access archive for the deposit and dissemination of scientific research documents, whether they are published or not. The documents may come from teaching and research institutions in France or abroad, or from public or private research centers.
L'archive ouverte pluridisciplinaire HAL, est destinée au dépôt et à la diffusion de documents scientifiques de niveau recherche, publiés ou non, émanant des établissements d'enseignement et de recherche français ou étrangers, des laboratoires publics ou privés. 


\section{Accepted Manuscript}

Title: The alkyl chain length of

3-alkyl-3', 4',5,7-tetrahydroxyflavones modulates effective

inhibition of oxidative damage in biological systems:

illustration with LDL, red blood cells and human skin

keratinocytes

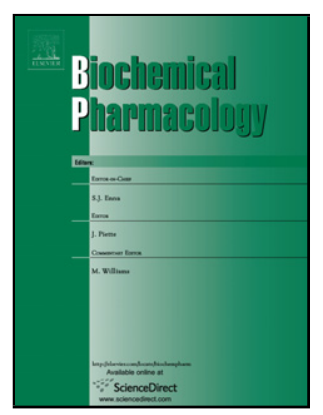

Authors: Paulo Filipe, Artur M.S. Silva, Raquel S.G.R.

Seixas, Diana C.G.A. Pinto, Alvaro Santos, Larry K.

Patterson, João N. Silva, José A.S. Cavaleiro, João P. Freitas,

Jean-Claude Mazière, René Santus, Patrice Morlière

PII:

S0006-2952(08)00857-5

DOI:

doi:10.1016/j.bcp.2008.11.023

Reference:

BCP 10026

To appear in: $\quad B C P$

Received date: $\quad 25-10-2008$

Revised date: $\quad 20-11-2008$

Accepted date: $\quad 21-11-2008$

Please cite this article as: Filipe P, Silva AMS, Seixas RSGR, Pinto DCGA, Santos A, Patterson LK, Silva JN, Cavaleiro JAS, Freitas JP, Mazière J-C, Santus R, Morlière P, The alkyl chain length of 3-alkyl-3',4',5,7-tetrahydroxyflavones modulates effective inhibition of oxidative damage in biological systems: illustration with LDL, red blood cells and human skin keratinocytes, Biochemical Pharmacology (2008), doi:10.1016/j.bcp.2008.11.023

This is a PDF file of an unedited manuscript that has been accepted for publication. As a service to our customers we are providing this early version of the manuscript. The manuscript will undergo copyediting, typesetting, and review of the resulting proof before it is published in its final form. Please note that during the production process errors may be discovered which could affect the content, and all legal disclaimers that apply to the journal pertain. 


\section{The alkyl chain length of 3-alkyl-3',4',5,7-tetrahydroxyflavones modulates effective inhibition of oxidative damage in biological systems: illustration} with LDL, red blood cells and human skin keratinocytes

Paulo Filipe ${ }^{a}$, Artur M.S. Silva ${ }^{b}$, Raquel S. G. R. Seixas, ${ }^{b}$ Diana C. G. A. Pinto, ${ }^{b}$ Alvaro Santos $^{a}$, Larry K. Patterson ${ }^{c, d}$, João N. Silva, ${ }^{a, d}$,José A.S. Cavaleiro ${ }^{b}$, João P. Freitas ${ }^{a}$, Jean-Claude Mazière ${ }^{d}$, René Santus ${ }^{e}$ and Patrice Morlière ${ }^{d, *}$

${ }^{\text {a }}$ Faculdade de Medicina de Lisboa, Clínica de Dermatologia, 1699 Lisboa, Portugal.

${ }^{\mathrm{b}}$ University of Aveiro, Department of Chemistry and OOPNA, 3810-193 Aveiro, Portugal.

${ }^{\mathrm{c}}$ University of Notre Dame, Radiation Laboratory, Notre Dame, Indiana 46556, USA.

d INSERM, ERI 12, 80054 Amiens, France; Université de Picardie Jules Verne, Faculté de Médecine et de Pharmacie, 80036 Amiens, France; CHU Amiens Nord, Laboratoire de Biochimie, 80054 Amiens, France.

e INSERM, U 697, 75475 Paris, France; Muséum National d'Histoire Naturelle, Département RDDM, 75231 Paris, France.

\footnotetext{
* Corresponding author: Mailing address: INSERM ERI12, Laboratoire de Biochimie, CHU Amiens Nord, place Victor Pauchet, 80054 Amiens Cedex 01, France. Tel: +33 3226686 69; Fax: +33 3226689 17, morliere.patrice@chu-amiens.fr.
} 


\begin{abstract}
It is shown that the relationship between the alkyl chain length of 3-alkyl-3',4',5,7 tetrahydroxyflavones $(\mathrm{FnH})$ bearing alkyl chains of $\mathrm{n}=1,4,6,10$ carbons and their capacity to counter oxidative damage varies markedly with the nature of the biological system. In $\mathrm{Cu}^{2+}$-induced lipid peroxidation of low-density lipoprotein (LDL), the less hydrophobic shortchain $\mathrm{F} 1 \mathrm{H}$ and $\mathrm{F} 4 \mathrm{H}$ are probably located in the outer layer of LDL and parallel the reference flavonoid antioxidant, quercetin (Q) as effective inhibitors of lipid peroxidation. A marked inhibition of haemolysis induced in red blood cells (RBC) suspensions by the membranepermeant oxidant, tert-butylhydroperoxide $(\mathrm{t}-\mathrm{BuOOH})$, is observed with $\mathrm{F} 4 \mathrm{H}$ and $\mathrm{F} 6 \mathrm{H}$ present at concentration in the micromolar range. However, $\mathrm{F} 10 \mathrm{H}$ the most hydrophobic $\mathrm{FnH}$ is even more effective than Q against both haemolysis and lipid peroxidation as measured by malondialdehyde (MDA) equivalents. In oxidation of $\mathrm{RBC}$ by $\mathrm{H}_{2} \mathrm{O}_{2}$, at least 50 times more $\mathrm{F} 6 \mathrm{H}$ and $\mathrm{F} 10 \mathrm{H}$ than by $\mathrm{t}-\mathrm{BuOOH}$ are required to only partly inhibit haemolysis and MDA production. The $\mathrm{F} 1 \mathrm{H}, \mathrm{F} 4 \mathrm{H}$ and $\mathrm{Q}$ are found rather inactive under these conditions. At concentrations in the micromolar range, a marked protection against the cytotoxic effects of the t-BuOOH-induced oxidative stress in human skin NCTC 2544 keratinocytes is also exhibited by the four FnH antioxidants and is comparable to that of Q. Thus, the four FnH species under study may be considered as potent antioxidants which manifest complementary anti-oxidative actions in biological systems of markedly different complexity.
\end{abstract}

Keywords: lipid peroxidation, hydrogen peroxide, tert-butylhydroperoxide, flavonoid, quercetin, cytotoxicity 


\section{Introduction}

It is well established that flavonoids present in large quantities in vegetables and fruits exhibit antioxidant properties. Their antioxidant activity has been attributed: (a) to the presence of a catechol moiety in the B-ring; (b) to the 4'-OH group conjugated with the $3-\mathrm{OH}$ or 4-keto functions of the $\mathrm{C}$-ring through the $\mathrm{C} 2=\mathrm{C} 3$ double bond; (c) to the presence of 3 - and 5hydroxyl groups in the flavone molecular structure $[1,2]$. The antioxidant effectiveness of hydroxyflavones has also been related to the number of hydroxyl groups in the molecule, and also to their hydrogen radical donating abilities [2]. In relation to their antioxidant properties, beneficial effects of flavones have also been reported for cancer [3], bacterial [1, 4] or viral infections [5] and inflammatory diseases $[4,6]$.

Numerous investigations have demonstrated that the flavonol quercetin (Q) [1] and the flavone luteolin $[2,7]$ are powerful antioxidants. Recent studies have revealed that lipophilic flavones bearing methyl, isopropyl, benzyl, or isoprenyl groups enhance the binding affinity towards P-glycoprotein and diminish cancer cell chemoresistance [3]. In light of these several reports, we have synthesized a series of novel 3-alkyl-3',4',5,7-tetrahydroxyflavones $(\mathrm{FnH})$ bearing alkyl chains of $n=1,4,6$ or 10 carbons [8]. It is hoped that by varying the lipophilic 3-alkyl chain length of these luteolin analogues, one may promote interesting biochemical properties. For example, these compounds, which lack the hydroxyl group at C-3 position-a major site of conjugation in vivo - may have better pharmacokinetics in humans than other types of polyhydroxyflavones, e.g. Q, which are not effectively transferred from the digestive lumen into the blood stream and which additionally, are extensively metabolized [9]. Furthermore, related 3-alkyl-3',4'-dihydroxypolymethoxyflavone derivatives are known to inhibit arachidonate 5-lipoxygenase [10].

Recently, we have demonstrated that all the FnH species synthesized are effective inhibitors of ${ }^{\circ} \mathrm{O}_{2}^{-}$radical-anions, a model reactive oxygen species (ROS) of biological 
significance. In addition, they can repair radical induced damage to Trp, an aromatic aminoacid essential to the structure and function of many proteins [11]. We have also shown that using $\mathrm{FnH}$ antioxidants of increasing alkyl chain length provides control of oxidation processes at various depths in organized microstructures such as ionic or neutral micelles. Significantly, they can act to stabilize such micro-heterogeneous structures. The observed dependence of radical kinetics on alkyl structures in these model systems is important from a biological viewpoint, and suggests a fruitful study of the effectiveness of these new antioxidants whose cellular distribution may be selectively modulated. In view of the results in micellar environments, we have investigated the capacity of these 3-alkyl-3',4',5,7tetrahydroxyflavones to control oxidative processes in several well-established biologically relevant but structurally different model systems. In this manner, we hope to elucidate possible structurally-dependent chain length effects on selected biological activities. The biological model systems chosen for these studies include blood LDL, RBC and human skin keratinocytes.

Here we have compared the ability of the four FnH species to inhibit the $\mathrm{Cu}^{2+}$-induced lipid peroxidation of LDL. In the cellular studies, RBC haemolysis and cytotoxic effects in keratinocytes were utilized as markers of cell injuries. In measurements with RBC and keratinocytes, oxidative stress has been generated by the amphiphatic t-BuOOH, a stable organic hydroperoxide and $\mathrm{H}_{2} \mathrm{O}_{2}$. In all the cases, the protection afforded by $\mathrm{FnH}$ has been compared to that of $\mathrm{Q}$, one of the most effective natural flavonoid antioxidant in the $\mathrm{Cu}^{2+}$ induced lipid peroxidation of LDL $[2,12,13]$ and in oxidative stress-related cytotoxic effects [14].

\section{Materials and methods}

\subsection{Chemicals and routine equipment}


All routine chemicals were of analytical grade and were used as received from the suppliers. Quercetin dihydrate $(\mathrm{Q}), \mathrm{t}-\mathrm{BuOOH}$ and sodium dodecyl sulfate (SDS) were purchased from Sigma Chemical (Saint-Louis, MO, USA). Dimethyl sulfoxide (DMSO), $\mathrm{H}_{2} \mathrm{O}_{2}$ and absolute ethanol were supplied by Merck and were of spectroscopic grade. The phosphate buffer $(\mathrm{pH}$ 7.4) was prepared in pure water obtained with a reverse osmosis system from Millipore. This water exhibits a resistivity of $>18 \mathrm{MOhms} \mathrm{cm}^{-1}$ and a total organic content of $<10 \mathrm{ppb}$. Absorption spectrophotometry was carried out with an Uvikon 922 spectrophotometer whereas fluorescence spectra were recorded with a Shimadzu RF5000 spectrofluorometer.

The 3-alkyl-3',4',5,7-tetrahydroxyflavones (Scheme 1) were synthesized as described in the literature [8]. They have been abbreviated as FnH in accordance with our preceding article on their redox properties [11].

\subsection{Preparation and treatment of $L D L$}

Serum samples were obtained from healthy volunteers. The LDL $(d=1.024-1.050 \mathrm{~g} / \mathrm{mL})$ was prepared by sequential ultracentrifugation according to Havel et al. [15]. Protein content was determined by the technique of Peterson [16]. The LDL samples were used within 2-3 weeks of preparation. Just before experimentation, LDL was dialyzed twice for 8 and $16 \mathrm{~h}$ against 1 liter of $10 \mathrm{mM}$ phosphate buffer $(\mathrm{pH}$ 7.4) to remove EDTA and then was diluted to a final concentration of $0.15 \mathrm{mg}$ protein $/ \mathrm{mL}(300 \mathrm{nM})$. Subsequently, $150 \mu \mathrm{L}$ of $5 \mu \mathrm{M}$ solutions of FnH or of Q in $10 \mathrm{mM}$ phosphate buffer were added to $800 \mu \mathrm{L}$ of the diluted LDL. Blank LDL solutions without FnH or Q were also prepared. The LDL solutions loaded with FnH or $\mathrm{Q}$ and the blank LDL solutions were then incubated at $37{ }^{\circ} \mathrm{C}$ for $15 \mathrm{~min}$. Lipid peroxidation was initiated by adding $50 \mu \mathrm{L}$ of $100 \mu \mathrm{M}$ aqueous $\mathrm{Cu}^{2+}$ solution to produce a final concentration of $5 \mu \mathrm{M} \mathrm{Cu}^{2+}$ in the incubation medium.

\subsection{Conjugated diene determination and consumption of carotenoids}


Conjugated diene formation was monitored by measuring the increase in absorbance at 234 $\mathrm{nm}$ and was determined periodically during incubation at $37{ }^{\circ} \mathrm{C}$. Changes in carotenoid concentration during LDL oxidation were monitored by second derivative absorption spectroscopy $(400-550 \mathrm{~nm})$ through measurement of the second derivative spectrum amplitude between 489 and $516 \mathrm{~nm}$ and were then expressed as percent of the initial concentration[17]. In human plasma, four carotenoids, $\alpha$-carotene, $\beta$-carotene, $\beta$ cryptoxanthin and lycopene are the principle contributors to the absorbance in the 400-550 $\mathrm{nm}$ region $[18,19]$.

\subsection{Fluorometric determination of the ApoB-100 Trp loss}

The concentration of intact Trp residues in the apolipoprotein was determined in native LDL solutions $(240 \mathrm{nM})$ following a previously published procedure [20]. The fluorescence of the Trp residues was excited at $292 \mathrm{~nm}$, a wavelength absorbed specifically by these residues. Under these conditions, the contribution of the vitamin E fluorescence is negligible [20, 21]. The fluorescence of the LDL solutions was recorded every $10 \mathrm{~min}$ in order to obtain accurate degradation kinetics at $37^{\circ} \mathrm{C}$.

\subsection{Preparation and treatment of red blood cells}

Venous blood was collected from healthy volunteers. Red blood cells were then separated from heparinized blood by centrifugation at $2000 \mathrm{~g}$ for $10 \mathrm{~min}$ and used immediately after 3 washings with ice-cold physiological saline. Red blood cell suspensions were prepared with $10 \mathrm{mM}$ phosphate buffer in $150 \mathrm{mM} \mathrm{NaCl}(\mathrm{pH} 7.4)$ to obtain a final concentration of $2.5 \%$ $(\mathrm{v} / \mathrm{v})$. In the case of experiments with hydrogen peroxide as the oxidant, the erythrocyte suspensions were pre-incubated with $2 \mathrm{mM}$ sodium azide for $1 \mathrm{~h}$ at $37^{\circ} \mathrm{C}$ in a shaking water bath. The percent of hemolysis was spectrophotometrically determined according to the method of Kellogg and Fridovich by measuring the absorbance change at $409 \mathrm{~nm}, 100 \%$ hemolysis being obtained by an osmotic shock with distilled water [22]. The extent of lipid 
peroxidation in $\mathrm{RBC}$ was estimated by measuring the fluorescence of thiobarbituric acid reactive substances (TBARS) as already described [23]. The TBARS levels were expressed as MDA equivalents in units of $\mathrm{nmol} / \mathrm{g}$ haemoglobin [23]. The acid hydrolysis of 1,1,3,3tetraethoxypropane which yields MDA was used for calibrating TBARS fluorescence [17]. Haemoglobin concentration was estimated spectrophotometrically by the cyanmethemoglobin method [23]. The t-BuOOH, $\mathrm{H}_{2} \mathrm{O}_{2}, \mathrm{Q}$ and $\mathrm{FnH}$ stock solutions in DMSO were added to diluted red cell suspensions to obtain the desired final concentrations. tertButylhydroperoxide and hydrogen peroxide were always added 15 min after the $\mathrm{FnH}$.

\subsection{Cell culture and treatment}

The NCTC 2544 immortalized human skin keratinocyte cell line was purchased from ICN Flow (Fontenay sous Bois, France). Cultures were propagated in minimum essential medium with Earle's salts (EMEM) supplemented with $10 \%$ foetal calf serum (FCS), $100 \mathrm{U} / \mathrm{mL}$ penicillin and $100 \mu \mathrm{g} / \mathrm{mL}$ streptomycin (weekly passages, 1:10 splitting ratio). Cells from trypsinized confluent monolayers were seeded at a density of $15,000 \mathrm{cells} / \mathrm{cm}^{2}$ on plates with 24 wells of about $2 \mathrm{~cm}^{2}$ each, containing $1 \mathrm{~mL}$ of complete medium (EMEM supplemented with FCS). These were grown for 4 days to about $75 \%$ of confluency. After two washings with $1 \mathrm{~mL}$ of phosphate buffer saline (PBS), cells were incubated for $1 \mathrm{~h}$ at $37{ }^{\circ} \mathrm{C}$ with 250 $\mu \mathrm{L}$ of FnH in PBS at the desired concentration. Then, after addition of $5 \mathrm{mM}$ t-BuOOH (from $0.125 \mathrm{M}$ stock solutions in PBS) and incubation for $2 \mathrm{~h}$ with the oxidant, cells were washed and further incubated for $2 \mathrm{~h}$ at $37{ }^{\circ} \mathrm{C}$ in complete medium. After two washings with PBS, the challenged cells were submitted to the viability assay with Neutral Red (NR). The $2 \mathrm{~h}$ lag between treatment and assay was chosen to allow the initial damage to propagate but was short enough to avoid important proliferation of undamaged cells (population doubling time is about 1 day) which may obscure the effect of the oxidative stress.

\subsection{Neutral Red uptake assay}


The cytotoxicity of t-BuOOH on NCTC 2544 keratinocytes, was determined by the widely used NR uptake assay [24, 25]. It has been validated by the European Union for testing phototoxic chemicals and for the classification and labelling of hazardous chemicals (EU Commission Directive 2000/33/EC). The day before the assay, a saturated aqueous NR solution was diluted $(1: 80 \mathrm{v} / \mathrm{v})$ with complete medium and left overnight at $37{ }^{\circ} \mathrm{C}$. Just before use, this NR solution was centrifuged twice to eliminate excess NR precipitate. Challenged cells were washed and incubated with $250 \mu \mathrm{L}$ of this NR solution for $2 \mathrm{~h}$ at $37^{\circ} \mathrm{C}$. Then, after 3 washings with PBS, $400 \mu \mathrm{L}$ of a $1 \%$ SDS solution in water were added to solubilise cells and absorbance was read at $550 \mathrm{~nm}$ in 96 microwell plates. Data are presented as the percentage of NR uptake with respect to that of a control experiment carried out in the absence of oxidant. The data are the mean $\pm \mathrm{SD}$ of at least three independent experiments, each performed in triplicates.

\section{Results and discussion}

\subsection{Inhibition of conjugated diene formation and carotenoid bleaching by FnH during $L D L$} oxidation

Low density lipoprotein is a natural carrier of important antioxidants such as vitamin $\mathrm{E}$ and carotenoids. In the four LDL preparations we used for this set of experiments, the vitamin E $/ \mathrm{LDL}$ and $\beta$-carotene/LDL concentration ratios $(\mathrm{mol} / \mathrm{mol})$ were $6.72 \pm 0.72$ and $0.40 \pm 0.25$ respectively as determined by HPLC [26]. These antioxidants inhibit LDL lipid peroxidation until they are consumed. An induction period or lag time is thus observed between the start of the oxidation by $\mathrm{Cu}^{2+}$ ions and the appearance of lipid peroxidation products. The duration of this induction period depends on the constitutive antioxidant content of LDL which may vary among blood donors [27]. Figure 1A shows the time course of the conjugated diene formation after addition of $5 \mu \mathrm{M} \mathrm{Cu}^{2+}$ to $240 \mathrm{nM}$ of native LDL occurring in the absence or in the presence of $0.75 \mu \mathrm{M} F n H$ or Q. It may be seen that under these conditions the lipid 
peroxidation in the absence of $\mathrm{FnH}$ begins almost immediately after $\mathrm{Cu}^{2+}$ addition. The time lapse for producing $50 \%$ of the conjugated dienes obtained at plateau (CD50) is $\sim 70 \mathrm{~min}$. Addition of F1H, F4H or Q totally inhibits the formation of conjugated dienes during $\sim 50$ min of incubation at $37^{\circ} \mathrm{C}$ and shifts the $\mathrm{CD} 50$ to $\sim 2 \mathrm{~h}$. By contrast, $\mathrm{F} 6 \mathrm{H}$ and $\mathrm{F} 10 \mathrm{H}$ only increase the CD50 by $\sim 30 \%$ compared to that in control solution containing no antioxidants. Thus, in the $\mathrm{Cu}^{2+}$-induced LDL oxidation model, F1H and F4H can be considered to be as good an antioxidant as $\mathrm{Q}$, one of the most potent polyphenol antioxidant $[2,28]$.

To further characterise the order of antioxidant effectiveness $\mathrm{F} 4 \mathrm{H}>\mathrm{F} 1 \mathrm{H}=\mathrm{Q}>>\mathrm{F} 6 \mathrm{H}=$ F10H established from Fig. 1A data, carotenoid consumption was also monitored under the same experimental conditions. Figure 1B suggests similar inhibition of the carotenoid consumption by the $\mathrm{FnH}$ derivatives, $\mathrm{F} 1 \mathrm{H}$, again being equivalent to $\mathrm{Q}$ in effective protection. These data support several structure-activity relationships regarding the antioxidant capacity of the $\mathrm{FnH}$ species as a function of 3-alkyl chain length. $\mathrm{FnH}$ is hydrophobic and readily solubilises in the LDL solution but not in buffer, suggesting that FnH must incorporate into LDL particles at some level. On the basis of results obtained with our preceding study in micellar media [11], the large variation observed here in antioxidant effectiveness may be due to differing FnH locations in LDL as a function of the alkyl chain length. Owing to their four hydroxyl groups $\mathrm{F} 1 \mathrm{H}$ and, to a lesser extent, $\mathrm{F} 4 \mathrm{H}$ are expected to be located in the water-rich outer layer constituted of phospholipids, cholesterol and ApoB-100 apolipoprotein which enwraps the LDL particle and contributes to its solubility in plasma. Indeed, addition of 0.75 $\mu \mathrm{M}$ of non fluorescent $\mathrm{F} 1 \mathrm{H}$ to the $240 \mathrm{nM}$ LDL solution induces a $7 \%$ quenching of Trp residue fluorescence suggesting close interaction between $\mathrm{F} 1 \mathrm{H}$ and some Trp residues of ApoB-100 (data not shown). On the other hand, the longer alkyl tails of F6H and F10H most probably favour hydrophobic interactions with the LDL lipid core, thereby moving the polyhydroxyphenol head groups more deeply in the LDL particle. Because of the binding of 
$\mathrm{Cu}^{2+}$ ions to ApoB-100, the initial targets of the LDL oxidation by $\mathrm{Cu}^{2+}$ are 8-9 Trp residues of ApoB-100, and is a vitamin E-independent process [21]. The resulting formation of indolyl radicals (Trp") triggers the radical chain reactions of peroxidation of LDL lipids most probably located in the vicinity of the oxidized Trp residues [21]. These Trp radicals are not repaired by vitamin $\mathrm{E}$ or $\beta$-carotene [26]. With the assumption that Trp residues are the initial targets of Apo-B-bound $\mathrm{Cu}^{2+}$ ions, $\mathrm{F} 1 \mathrm{H}-$ the least hydrophobic $\mathrm{FnH}-$ is expected to be the most effective antioxidant by consequence of its proximity to these Trp residues and its ability to repair them [11] thus impeding the initiation of LDL lipid peroxidation. In this regard, Fig. 2A shows that although in the absence of $\mathrm{Cu}^{2+}$ ions LDL-bound $\mathrm{Q}$ can repair ApoB-100 radical species [29], addition of $0.75 \mu \mathrm{M} \mathrm{Q}$ may actually accelerate $\mathrm{Cu}^{2+}$ ion-induced $\operatorname{Trp}$ residue destruction. By contrast, the same concentration of $\mathrm{F} 1 \mathrm{H}$ provides a level of protection. Additionally, the ability of FnH to neutralize reactive oxygen species (ROS) by hydrogen donation [11] and to form complexes with $\mathrm{Cu}^{2+}$ ions (Fig. 2B) must also contribute to the observed inhibition. Taking into account all these observations, it can be seen that the present experimental system defines an overall apparent antioxidant capacity of these $\mathrm{FnH}$ antioxidants.

\subsection{Inhibition of lysis and membrane lipid peroxidation of red blood cells by FnH}

tert-Butylhydroperoxide is a membrane-permeant oxidant extensively used to induce oxidative stress in different systems [30, 31]. Its tert-butyl group confers lipid solubility. It thus easily penetrates membranes and is rapidly transferred to the cytosol. Here it is metabolized by the GSH peroxidase-reductase system with consumption of GSH and NADPH. When this enzymatic system is overwhelmed, a one-electron oxidation (or reduction) process mediated by catalytically active metal ions (for example, cytochrome P450) initially gives rise to radicals comparable to those encountered in the chain reaction of lipid peroxidation (peroxyl or alkoxyl radicals). These eventually rearrange and decompose 
into carbon-centered radicals such as methyl radicals. Such t-BuOOH-derived radicals are responsible for the lethal effects observed and trigger free radical chain reactions in membranes [32-34]. Trotta et al. have demonstrated that t-BuOOH degrades haemoglobin and provokes lipid peroxidation in RBC [34 and references therein]. A concentration of $0.6 \mathrm{mM} \mathrm{t}$ $\mathrm{BuOOH}$ and an incubation time of $60 \mathrm{~min}$ were found sufficient to induce about $15 \%$ haemolysis in human RBC suspensions and significant production of TBARS, the lipid peroxide decomposition products (Fig. 3 A,B). However, significant protection against haemolysis (Fig. 3A) in the presence of only $1.5 \mu \mathrm{M} \mathrm{F} 4 \mathrm{H}, \mathrm{F} 6 \mathrm{H}$ or F10H was observed. The diminution of RBC lysis was accompanied by a marked reduction of TBARS formation with F10H being again the most effective (Fig. 3B). It should be noted that under comparable experimental conditions, $\mathrm{F} 4 \mathrm{H}$, or $\mathrm{F} 6 \mathrm{H}$ or $\mathrm{F} 10 \mathrm{H}$ are proven to be much better inhibitors of RBC haemolysis and lipid peroxidation than 2,6-bis(1,1-dimethylethyl)-4-methylphenol (butylated hydroxytoluene), the well established lipid-soluble anti-oxidant [34]. By contrast, F1H was found to be essentially inactive in this system.

It has long been known that $\mathrm{H}_{2} \mathrm{O}_{2}$ causes haemolysis and lipid peroxidation of $\mathrm{RBC}$ [35]. Hence it is of interest to compare the capacity of the various FnH species to protect RBC from the oxidative stress induced by $\mathrm{H}_{2} \mathrm{O}_{2}$ to that observed with $\mathrm{t}-\mathrm{BuOOH}$ since appreciable differences in their biological action have been reported [36]. Hydrogen peroxide, a natural oxidant, diffuses across hydrophobic membranes and it is metabolized by GSH peroxidase and by catalase. Here, the latter was inhibited by addition of $\mathrm{NaN}_{3}$, potentiating the oxidative damage. Hydrogen peroxide reacts with redox metal ions by the so-called Fenton reactions to produce ${ }^{\circ} \mathrm{OH}$ radical, the strongest oxidizing species known (normal redox potential: $2.6 \mathrm{~V} v s$ NHE). As a result, ${ }^{\circ} \mathrm{OH}$ radicals react unselectively at their site of formation with all biological constituents, not just those targets critical for maintaining the integrity of structure and function. A 90 min incubation of the $\mathrm{RBC}$ with $10 \mathrm{mM} \mathrm{H}_{2} \mathrm{O}_{2}$ produces haemolysis (Fig. 
3A) and TBARS production (Fig. 3B) of the same order of magnitude as those obtained with $\mathrm{t}-\mathrm{BuOOH}$. However, in contrast to t-BuOOH, addition of at least $100 \mu \mathrm{M} \mathrm{F} 6 \mathrm{H}$ or $\mathrm{F} 10 \mathrm{H}$ is necessary to achieve the limited inhibition of RBC lysis $(30 \%)$ observed. In the case of TBARS measurements, replacing $\mathrm{F} 4 \mathrm{H}$ by $\mathrm{F} 6 \mathrm{H}$ or $\mathrm{F} 10 \mathrm{H}$ dramatically reduced TBARS production. At a concentration of $100 \mu \mathrm{M}$ neither $\mathrm{F} 1 \mathrm{H}$ nor $\mathrm{F} 4 \mathrm{H}$ significantly modified either TBARS formation or haemolysis.

The comparison of data from $\mathrm{RBC}$ obtained with t-BuOOH and $\mathrm{H}_{2} \mathrm{O}_{2}$ suggests that in both cases, the FnH species with the longest alkyl chain, and hence the most hydrophobic $-\mathrm{F} 10 \mathrm{H}$ and in a lesser extent $\mathrm{F} 6 \mathrm{H}$ - are the most effective protectors against haemolysis and lipid peroxidation. In all instances, Figs. $3 \mathrm{~A}$ and B suggest that they compare favorably with Q as antioxidants. By contrast, F4H can effectively protect against haemolysis but less ineffectively against lipid peroxidation only in the case of $\mathrm{t}-\mathrm{BuOOH}$-induced oxidative stress. In the light of the above discussion it is of note that $\mathrm{F} 1 \mathrm{H}$ and $\mathrm{F} 4 \mathrm{H}$ were quite effective in inhibiting the $\mathrm{Cu}^{2+}$-induced LDL lipid peroxidation but brought less protection to the $\mathrm{RBC}$, again supporting the suggestion of site-specific oxidation reactions at the LDL -water interface where $\mathrm{F} 1 \mathrm{H}$ and $\mathrm{F} 4 \mathrm{H}$ are probably localized.

\subsection{Inhibition of the t-BuOOH-induced oxidative stress by FnH in NCTC 2544 keratinocytes}

As skin is the interface between the body and the environment, there are numerous studies on cell disorders induced by various agents of oxidative and photo-oxidative stress. In addition to membrane lipid peroxidation, ROS have been shown to react in all skin cell compartments and with most cell structures. For example, they are responsible for impairment of cell signalling and activation of stress-sensitive protein kinases leading to enhanced production of cytokines. They also directly react with phosphatases or redox-sensitive proteins [for a review see ref. 37]. Because lipid peroxidation is the more relevant of the processes to radical induced skin damage, $\mathrm{t}-\mathrm{BuOOH}$ was preferred for this work, as it initially gives rise to 
oxygen radicals mimicking those encountered in lipid peroxidation. In this regard, it has been shown that $\mathrm{t}-\mathrm{BuOOH}$ is metabolized by freshly isolated or cultured normal human keratinocytes with production of cytotoxic free radicals leading to severe plasma membrane damage [38]. Given the large variety of skin related targets for t-BuOOH reported in the literature, we have chosen to follow an overall response to its oxidative stress. For this purpose, NR, a lysosomotropic dye which is only retained by intact lysosomes was used to assess the viability of the NCTC 2544 keratinocytes subjected to cytotoxic effects of t$\mathrm{BuOOH}$ in the absence or in the presence of the four $\mathrm{FnH}$ antioxidants.

Figure 4 demonstrates the strong cytotoxicity of $5 \mathrm{mM}$ t-BuOOH towards NCTC 2544 keratinocytes after a $2 \mathrm{~h}$ incubation at $37{ }^{\circ} \mathrm{C}$ in $\mathrm{PBS}$ in the absence of any FnH. Thus, after the initial damage had propagated for $2 \mathrm{~h}$ (see the experimental section), less than $20 \%$ of cells were found to have recovered from injury. Addition of only $0.5 \mu \mathrm{M}$ of all FnH species or of Q provided some protection to the keratinocytes. In the presence of $5 \mu \mathrm{M}$ of all the antioxidants, most cells survived the oxidative stress. However, a trend can be noted with slightly less protection by $\mathrm{F} 10 \mathrm{H}$ which has the longest alkyl chain length, while $\mathrm{F} 1 \mathrm{H}, \mathrm{F} 4 \mathrm{H}$ and $\mathrm{F} 6 \mathrm{H}$ are shown to be as effective as Q. In our previous kinetic study on the one-electron oxidation of the $\mathrm{FnH}$ by ${ }^{\circ} \mathrm{O}_{2}^{-}$radical-anions, we have shown that $\mathrm{F} 6 \mathrm{H}$ and $\mathrm{F} 10 \mathrm{H}$ can strongly increase the rigidity of hydrophobic microenvironments [11]. As a consequence, it may be hypothesized that the decyl tail on the $3^{\prime}, 4^{\prime}, 5,7$-tetrahydroxyflavones may somewhat hinder the translocation of $\mathrm{F} 10 \mathrm{H}$ from the plasma membrane to cell organelles, causing less overall protection.

\section{Conclusions}

As suggested by our very recent study on the high reactivity of the $3^{\prime}, 4{ }^{\prime}, 5,7$ tetrahydroxyflavones with ${ }^{\circ} \mathrm{O}_{2}{ }^{-}$radical-anions taken as model $\mathrm{ROS}$ and their ability to repair 'Trp radicals [11], the present work demonstrates that 3,3',4',5,7-tetrahydroxyflavones are 
potent antioxidants in the three model biological systems of increasing complexity examined here. Interestingly, the structure-activity relationships drawn from antioxidant protection provided by the various $\mathrm{FnH}$ antioxidants strongly depends on the model studied. Thus, significant effects are observed with $\mathrm{F} 1 \mathrm{H}$ and $\mathrm{F} 4 \mathrm{H}$ in the prevention of $\mathrm{LDL}$ oxidation by $\mathrm{Cu}$ ${ }^{2+}$ ions but have little or no effect on RBC lysis whereas the opposite situation hold for F6H and $\mathrm{F} 10 \mathrm{H}$. Our kinetic study on the reactivity of these $\mathrm{FnH}$ antioxidants shows that although there is no change in the intrinsic redox properties of the tetrahydroxyflavone ring, the apparent reactivity of FnH species are strongly modulated by their alkyl chain length. This parameter governs their partition in aqueous $v s$ hydrocarbon-like environments and may be related to increase the compactness of the hydrocarbon-like core [11]. Our present work suggests that the biological activity of these compounds may follow a similar rule. Finally, it is hoped that both the physico-chemical work and the present biochemical investigation may stimulate fruitful routes for studying new antioxidants whose cellular distribution may be selectively modulated.

\section{Acknowledgements}

This work was supported by the Franco-Portuguese exchange programs GRICES-INSERM 2005-2006 and Pessoa 07958NF. J.N. Silva thanks the "Sociedade Portugesa de Dermatologia e Venerologia" for a travel grant. Thanks are due to the University of Aveiro, "Fundação para a Ciência e a Tecnologia" and FEDER for funding the Organic Chemistry Research Unit and the Project POCI/QUI/59284/2004. RSGR Seixas also thanks FEDER and Project POCI/QUI/59284/2004 for funding a research grant.

\section{References}

[1] Rice-Evans C, Packer L. Flavonoids in Health Disease. New York: Marcel Dekker, 1998. 
[2] Rice-Evans CA, Miller NJ, Paganga G. Structure-antioxidant activity relationships of flavonoids and phenolic acids. Free Radic Biol Med 1996;20:933-56.

[3] Comte G, Daskiewicz JB, Bayet C, Conseil G, Viornery-Vanier A, Dumontet C, et al. C-Isoprenylation of flavonoids enhances binding affinity toward P-glycoprotein and modulation of cancer cell chemoresistance. J Med Chem 2001;44:763-8.

[4] Siedle B, Hrenn A, Merfort I. Natural compounds as inhibitors of human neutrophil elastase. Planta Med 2007;73:401-20.

[5] Fesen MR, Pommier Y, Leteurtre F, Hiroguchi S, Yung J, Kohn KW. Inhibition of HIV-1 integrase by flavones, caffeic acid phenethyl ester (CAPE) and related compounds. Biochem Pharmacol 1994;48:595-608.

[6] Loke WM, Proudfoot JM, Stewart S, McKinley AJ, Needs PW, Kroon PA, et al. Metabolic transformation has a profound effect on anti-inflammatory activity of flavonoids such as quercetin: lack of association between antioxidant and lipoxygenase inhibitory activity. Biochem Pharmacol 2008;75:1045-53.

[7] Chowdhury AR, Sharma S, Mandal S, Goswami A, Mukhopadhyay S, Majumder HK. Luteolin, an emerging anti-cancer flavonoid, poisons eukaryotic DNA topoisomerase I. Biochem J 2002;366:653-61.

[8] Seixas RSGR, Pinto DCGA, Silva AMS, Cavaleiro JAS. Synthesis of novel 3-alkyl-3'4'-5-7-tetrahydroxyflavones. Aus J Chem 2008;61:718-24.

[9] Mullen W, Edwards CA, Crozier A. Absorption, excretion and metabolite profiling of methyl-, glucuronyl-, glucosyl and sulpho-conjugates of quercetin in human plasma and urine after ingestion of onions. Br J Nutr 2006;96:107-16.

[10] Horie T, Tominaga H, Kawamura Y, Hada T, Ueda N, Amano Y, et al. Syntheses of 5,7,8- and 5,6,7-trioxygenated 3-alkyl-3',4'-dihydroxyflavones and their inhibitory activities against arachidonate 5-lipoxygenase. J Med Chem 1991;34:2169-76. 
[11] Silva AMS, Filipe P, Seixas RSGR, Pinto DCGA, Patterson LK, Hug GL, et al. Oneelectron reduction of superoxide radical-anions by 3-alkylpolyhydroxyflavones in micelles. Effect of antioxidant alkyl chain length on micellar structure and reactivity. J Phys Chem B 2008;112:11456-61.

[12] Cadenas E, Packer L. Handbook of Antioxidants. New York: Marcel Dekker, 1996.

[13] Filipe P, Silva AM, Morlière P, Brito CM, Patterson LK, Hug GL, et al. Polyhydroxylated 2-styrylchromones as potent antioxidants. Biochem Pharmacol 2004;67:2207-18.

[14] Filipe P, Silva JN, Haigle J, Freitas JP, Fernandes A, Santus R, et al. Contrasting action of flavonoids on phototoxic effects induced in human skin fibroblasts by UVA alone or UVA plus cyamemazine, a phototoxic neuroleptic. Photochem Photobiol Sci $2005 ; 4: 420-8$.

[15] Havel RJ, Eder HA, Bragdon JH. The distribution and chemical composition of ultracentrifugally separated lipoproteins in human serum. J Clin Invest 1955;34:134553.

[16] Peterson GL. Simplification of the protein assay method of Lowry et al. which is more generally applicable. Anal Biochem 1977;83:346-56.

[17] Filipe P, Haigle J, Freitas JP, Fernandes A, Mazière J-C, Mazière C, et al. Anti- and pro-oxidant effects of urate in copper-induced low-density lipoprotein oxidation. Eur J Biochem 2002;269:5474-83.

[18] Behrens WA, Thompson JN, Madère R. Distribution of alpha-tocopherol in human plasma lipoproteins. Am J Clin Nutr 1982;35:691-6.

[19] Thurnham DI, Smith E, Flora PS. Concurrent liquid-chromatography assay of retinol, $\alpha$-tocopherol, $\beta$-carotene, $\alpha$-carotene, lycopene and $\beta$-cryptoxanthin in plasma, with tocopherol acetate as internal standard. Clin Chem 1988;34:377-81. 
[20] Reyftmann J-P, Santus R, Mazière J-C, Morlière P, Salmon S, Candide C, et al. Sensitivity of tryptophan and related compound to oxidation induced by lipid autoperoxidation. Application to human serum low and high density lipoproteins. Biochim Biophys Acta 1990;1042:159-67.

[21] Giessauf A, Steiner E, Esterbauer H. Early destruction of tryptophan residues of apolipoprotein $\mathrm{B}$ is a vitamin E-independent process during copper-mediated oxidation of LDL. Biochim Biophys Acta 1995;1256:221-32.

[22] Kellogg EW, Fridovich I. Liposome and erythrocyte lysis by enzimically generated superoxide and hydrogen peroxide. J Biol Chem 1977;252:6721-5.

[23] Fernandes AC, Filipe PM, Freitas JP, Manso CF. Different effects of thiol and nonthiol ACE inhibitors on copper-induced lipid and protein oxidative modification. Free Radic Biol Med 1996;20:507-14.

[24] Silva JN, Haigle J, Tomé JP, Neves MG, Tomé AC, Mazière J-C, et al. Enhancement of the photodynamic activity of tri-cationic porphyrins towards proliferating keratinocytes by conjugation to poly-S-lysine. Photochem Photobiol Sci 2006;5:12633.

[25] Commission Directive 2000/33/EC. Official Journal of the European Communities 8.6.2000:L136/90-L/07.

[26] Boullier A, Mazière J-C, Filipe P, Patterson LK, Bartels DM, Hug GL, et al. Interplay of oxygen, vitamin E, and carotenoids in radical reactions following oxidation of Trp and Tyr residues in native $\mathrm{HDL}_{3}$. Comparison with LDL. A time-resolved spectroscopic analysis. Biochemistry 2007;46:5226-37.

[27] Esterbauer H, Striegl G, Puhl H, Rotheneder M. Continuous monitoring of in vitro oxidation of human low density lipoprotein. Free Rad Res Comms 1989;6:67-75. 
[28] Bors W, Heller W, Michel C, Saran M. Flavonoids as antioxidants: determination of radical-scavenging efficiencies. Methods Enzymol 1990;186:343-55.

[29] Filipe P, Morlière P, Patterson LK, Hug GL, Mazière J-C, Mazière C, et al. Repair of amino acid radicals of apolipoprotein B100 of low-density lipoproteins by flavonoids. A pulse radiolysis study with quercetin and rutin. Biochemistry 2002;41:11057-64.

[30] Geiger PG, Lin F, Girotti AW. Selenoperoxidase-mediated cytoprotection against the damaging effects of tert-butyl hydroperoxide on leukemia cells. Free Radic Biol Med 1993;14:251-66.

[31] Bellomo G, Martino A, Richelmi P, Moore GA, Jewell SA, Orrenius S. Pyridinenucleotide oxidation, $\mathrm{Ca}^{2+}$ cycling and membrane damage during tert-butyl hydroperoxide metabolism by rat-liver mitochondria. Eur J Biochem 1984;140:1-6.

[32] Davies MJ. Electron spin resonance studies on the degradation of hydroperoxides by rat liver cytosol. Free Rad Res Comms 1990;9:251-8.

[33] Sies H. Hydroperoxides and thiol oxidants in the study of oxidative stress in intact cells and organs. In: Sies E, editor. Oxidative Stress. New york: Academic Press, 1985. p. 73-90.

[34] Trotta RJ, Sullivan SG, Stern A. Lipid peroxidation and haemoglobin degradation in red blood cells exposed to t-butyl hydroperoxide. The relative roles of haem- and glutathione-dependent decomposition of t-butyl hydroperoxide and membrane lipid hydroperoxides in lipid peroxidation and haemolysis. Biochem J 1983;212:759-72.

[35] Stocks J, Dormandy TL. The autoxidation of human red cell lipids induced by hydrogen peroxide. Br J Haematol 1971;20:95-111.

[36] Awe SO, Adeagbo AS. Analysis of tert-butyl hydroperoxide induced constrictions of perfused vascular beds in vitro. Life Sci 2002;71:1255-66. 
[37] Bickers DR, Athar M. Oxidative stress in the pathogenesis of skin disease. J Invest Dermatol 2006;126:2565-75.

[38] Iannone A, Marconi A, Zambruno G, Giannetti A, Vannini V, Tomasi A. Free radical production during metabolism of organic hydroperoxides by normal human keratinocytes. J Invest Dermatol 1993;101:59-63. 


\section{Figure legends}

Figure 1A. Kinetics of conjugated diene formation during LDL oxidation induced by $5 \mu \mathrm{M}$ $\mathrm{Cu}^{2+}$. LDL solutions of $0.12 \mathrm{mg}$ protein $/ \mathrm{mL}(240 \mathrm{nM})$ final concentration in $10 \mathrm{mM}$ phosphate buffer (pH 7.4) were incubated for 15 min at $37^{\circ} \mathrm{C}$ with or without $0.75 \mu \mathrm{M} \mathrm{FnH}$ or $\mathrm{Q}$ before $\mathrm{Cu}^{2+}$ addition. Note that time zero denotes measurements made about 1 min after $\mathrm{Cu}^{2+}$ addition. Data are the mean $\pm \mathrm{SD}$ of four independent experiments. For clarity, SD are only shown for control and Q-loaded LDL.

Figure 1B. Kinetics of carotenoid consumption during LDL oxidation induced by $5 \mu \mathrm{M} \mathrm{Cu}^{2+}$. Experimental conditions are identical to those of Fig. 1A. Data are the mean \pm SD of four independent experiments. For clarity, SD are only shown for control and for Q-loaded LDL.

Figure 2A. Destruction of Trp residues during LDL oxidation induced by $5 \mu \mathrm{M} \mathrm{Cu}^{2+}$. LDL solutions of $0.12 \mathrm{mg}$ protein $/ \mathrm{mL}(240 \mathrm{nM})$ final concentration in $10 \mathrm{mM}$ phosphate buffer (pH 7.4) were incubated for 15 min at $37^{\circ} \mathrm{C}$ with or without $0.75 \mu \mathrm{M} \mathrm{F} 1 \mathrm{H}$ or Q before $\mathrm{Cu}^{2+}$ addition. The fluorescence of the LDL solutions (expressed in percent of the initial Trp fluorescence under excitation with $292 \mathrm{~nm}$ radiation) was recorded at $37{ }^{\circ} \mathrm{C}$ and measured at $10 \mathrm{~min}$ intervals. Note that time zero denotes measurements made immediately after $\mathrm{Cu}^{2+}$ addition. Data represent one experiment performed in duplicate.

Figure 2B. Spectra demonstrating the complexation of $\mathrm{Cu}^{2+}$ ions by $\mathrm{F} 1 \mathrm{H}$. Absorbance spectra of $100 \mu \mathrm{M} \mathrm{Cu}^{2+}$ and of $10 \mu \mathrm{M} \mathrm{F} 1 \mathrm{H}$ were measured in $10 \mathrm{mM}$ phosphate buffer $(\mathrm{pH} 7.4)$ at 20 ${ }^{\circ} \mathrm{C}$. The third spectrum corresponding to the $\mathrm{Cu}^{2+}+\mathrm{F} 1 \mathrm{H}$ mixture is a difference absorbance spectrum (sample cell: $10 \mu \mathrm{M} \mathrm{F1H}+100 \mu \mathrm{M} \mathrm{Cu}^{+}$, reference cell: $10 \mu \mathrm{M} \mathrm{F1H}$ ).

Figure 3A. Haemolysis (in percent) of RBC suspensions $(2.5 \% \mathrm{v} / \mathrm{v})$ in $10 \mathrm{mM}$ phosphate buffer (pH 7.4) after a $1 \mathrm{~h}$ incubation at $37{ }^{\circ} \mathrm{C}$ with $0.6 \mathrm{mM}$ t-BuOOH or after incubation for 90 min with $10 \mathrm{mM} \mathrm{H}_{2} \mathrm{O}_{2}$ in the absence (C) or in the presence of $\mathrm{FnH}$ or Q. The concentrations of FnH or Q were $1.5 \mu \mathrm{M}$ and $0.1 \mathrm{mM}$ for oxidation by t-BuOOH and $\mathrm{H}_{2} \mathrm{O}_{2}$, 
respectively. Data are the mean $\pm \mathrm{SD}$ of four independent experiments. Data are the mean \pm SD of four independent experiments. Analysis of variance was performed with an unpaired Student's t-test $(* \mathrm{p}<0.05, * * \mathrm{p}<0.01, * * * \mathrm{p}<0.005)$. (0) shows the haemolysis in the suspensions in the absence of any treatment. In the control (C), DMSO was added at a concentration corresponding to the dilution of stock solutions of the antioxidants (see text). A longer incubation time, a $1 \mathrm{~h}$ pre-incubation with $2 \mathrm{mM}$ sodium azide and a 5 -fold increased in DMSO concentration explain the increased hemolysis in controls of $\mathrm{H}_{2} \mathrm{O}_{2}$ experiments as compared to those with t-BuOOH.

Figure 3B. Production of MDA expressed in $\mathrm{nmol} / \mathrm{g}$ of haemoglobin in the $\mathrm{RBC}$ suspensions. The experimental conditions are the same as in Fig. 3A. Data are the mean \pm SD of four independent experiments. Analysis of variance was performed with an unpaired Student's ttest $(* \mathrm{p}<0.05, * * \mathrm{p}<0.01, * * * \mathrm{p}<0.005)$.

Figure 4. Effect of 3-alkyl-3',4',5,7-tetrahydroxyflavones (FnH) and of the flavonol quercetin (Q) on the cytotoxicity of 5mM t-BuOOH towards NCTC 2544 keratinocytes. Cells were incubated during $2 \mathrm{~h}$ in complete medium in the absence (C) or presence of several concentrations of antioxidants as indicated on the graph. The neutral red assay was performed $15 \mathrm{~h}$ after the incubation with $\mathrm{t}-\mathrm{BuOOH}$. Data are the mean $\pm \mathrm{SD}$ of four independent experiments in triplicate, with untreated cells taken as $100 \%$. Statistics were performed with an unpaired Student's t-test $\left({ }^{*} \mathrm{p}<0.05,{ }^{* *} \mathrm{p}<0.01,{ }^{* * *} \mathrm{p}<0.005\right)$. 


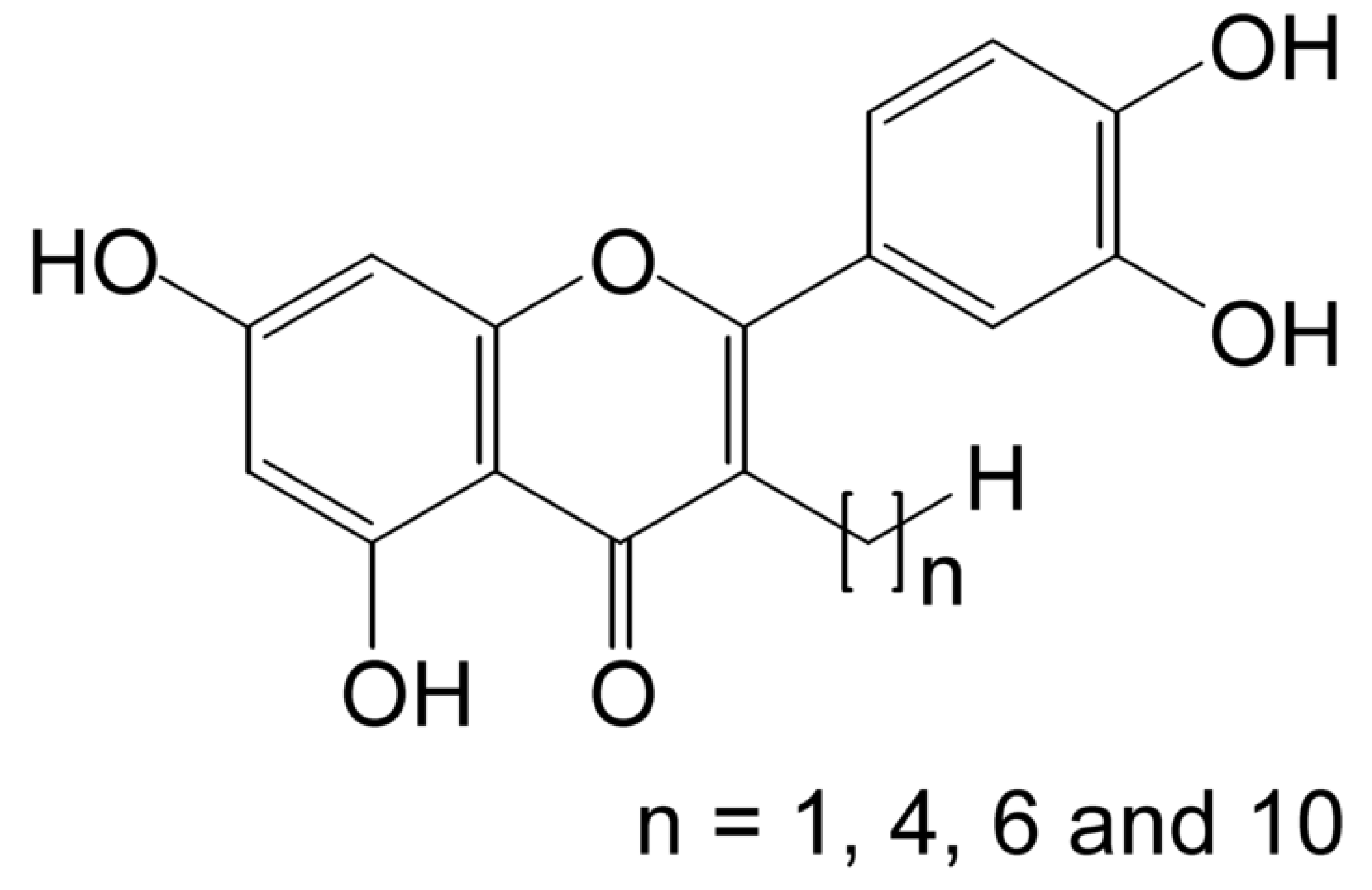

Page 22 of 26 

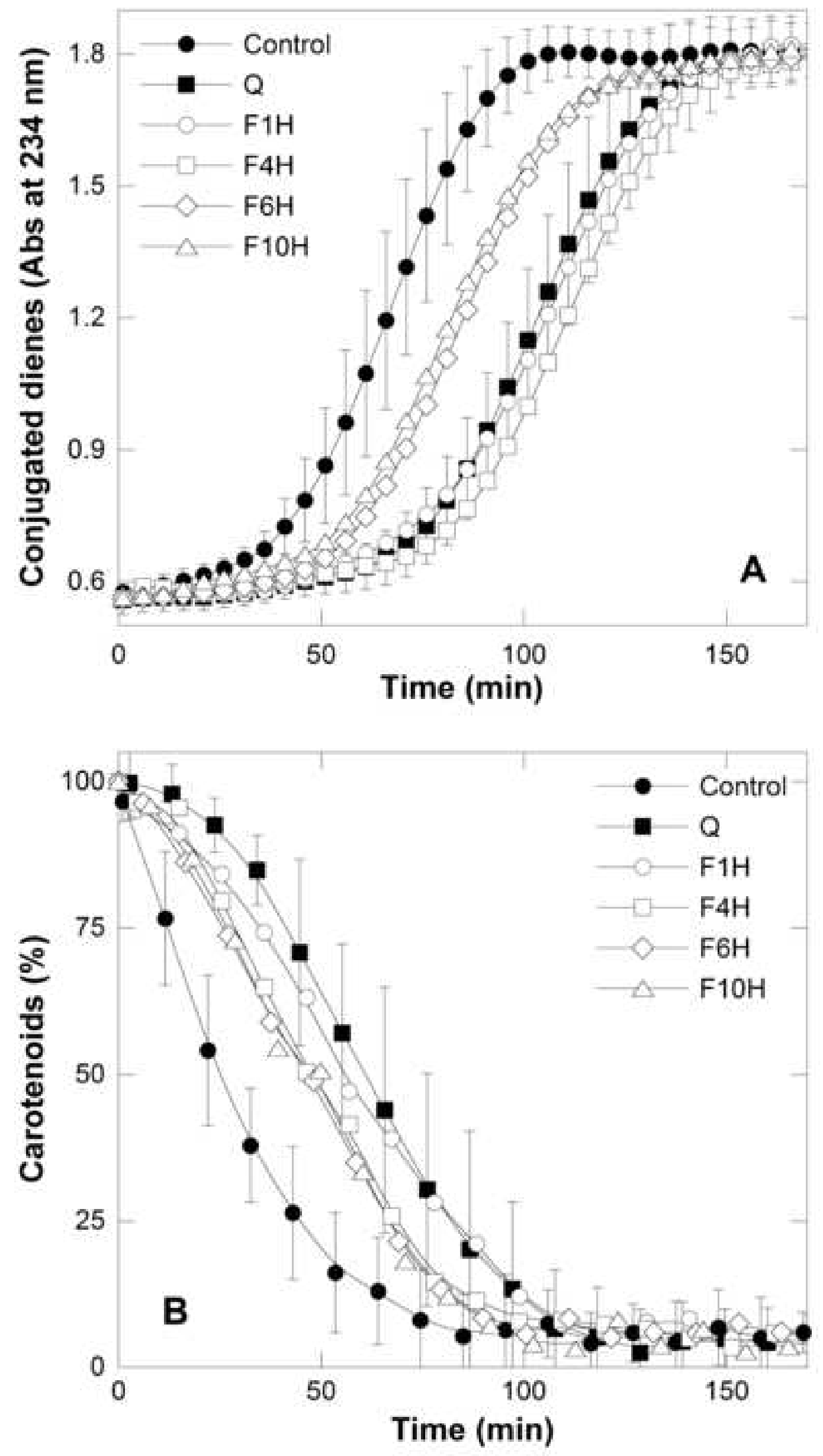

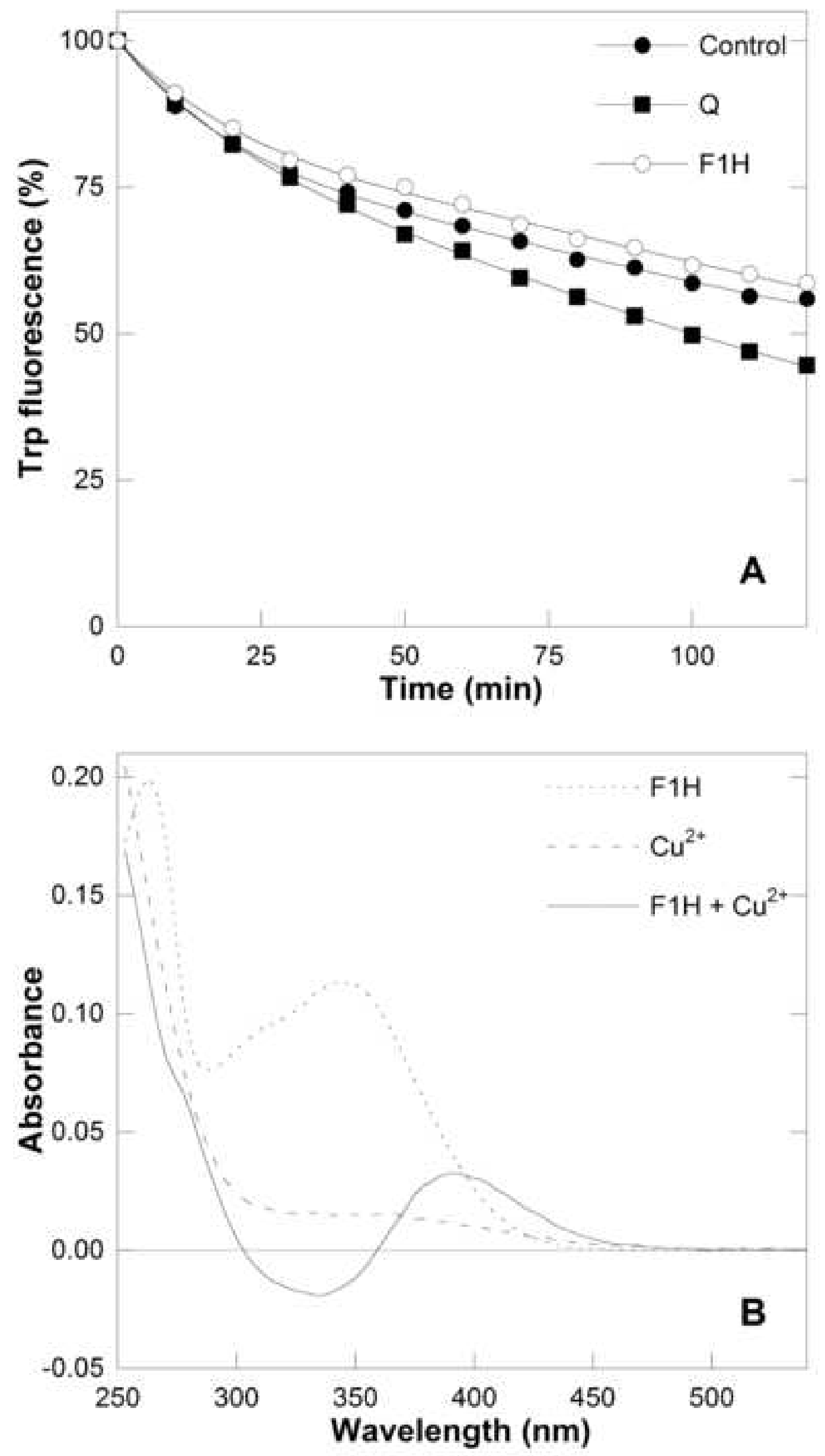

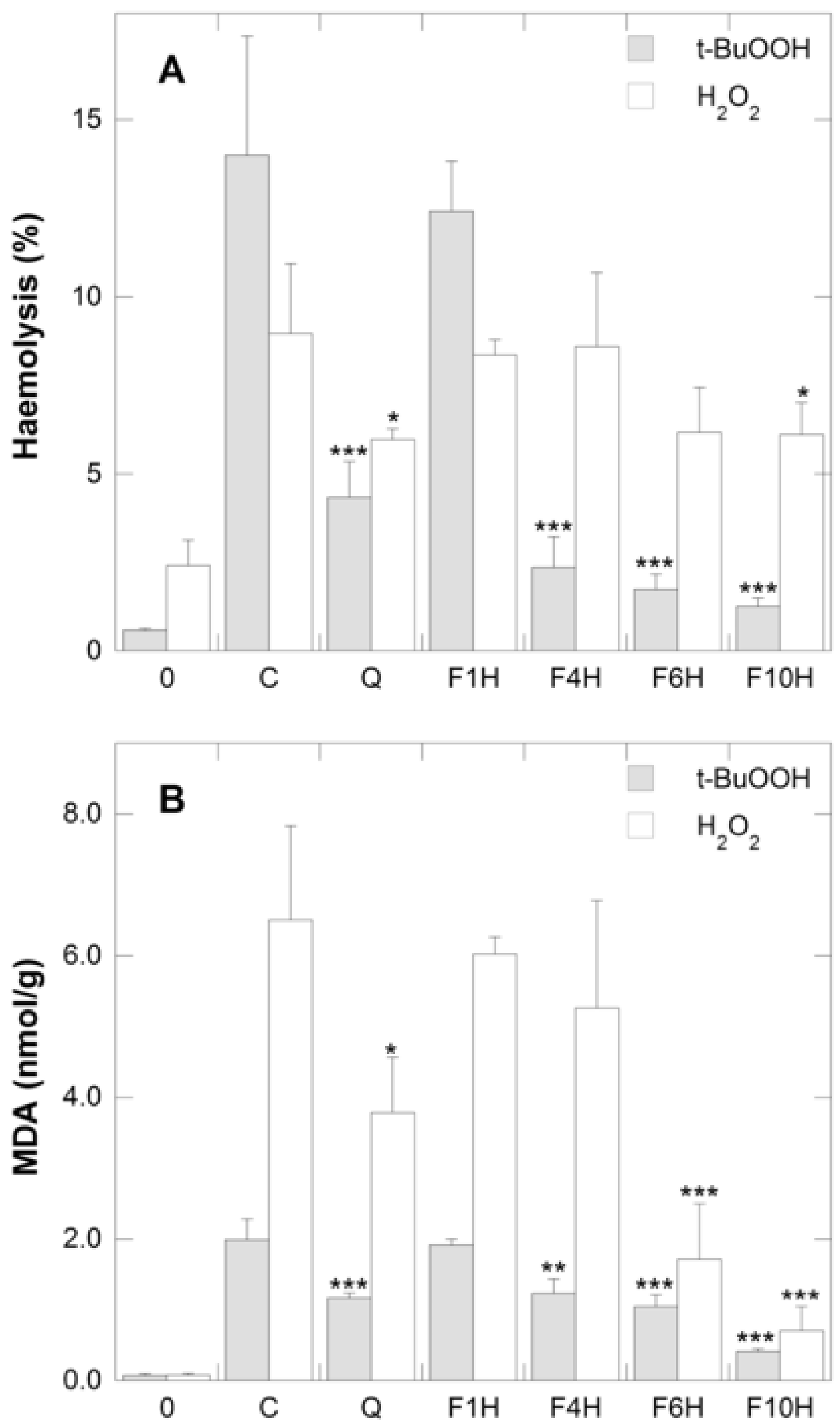


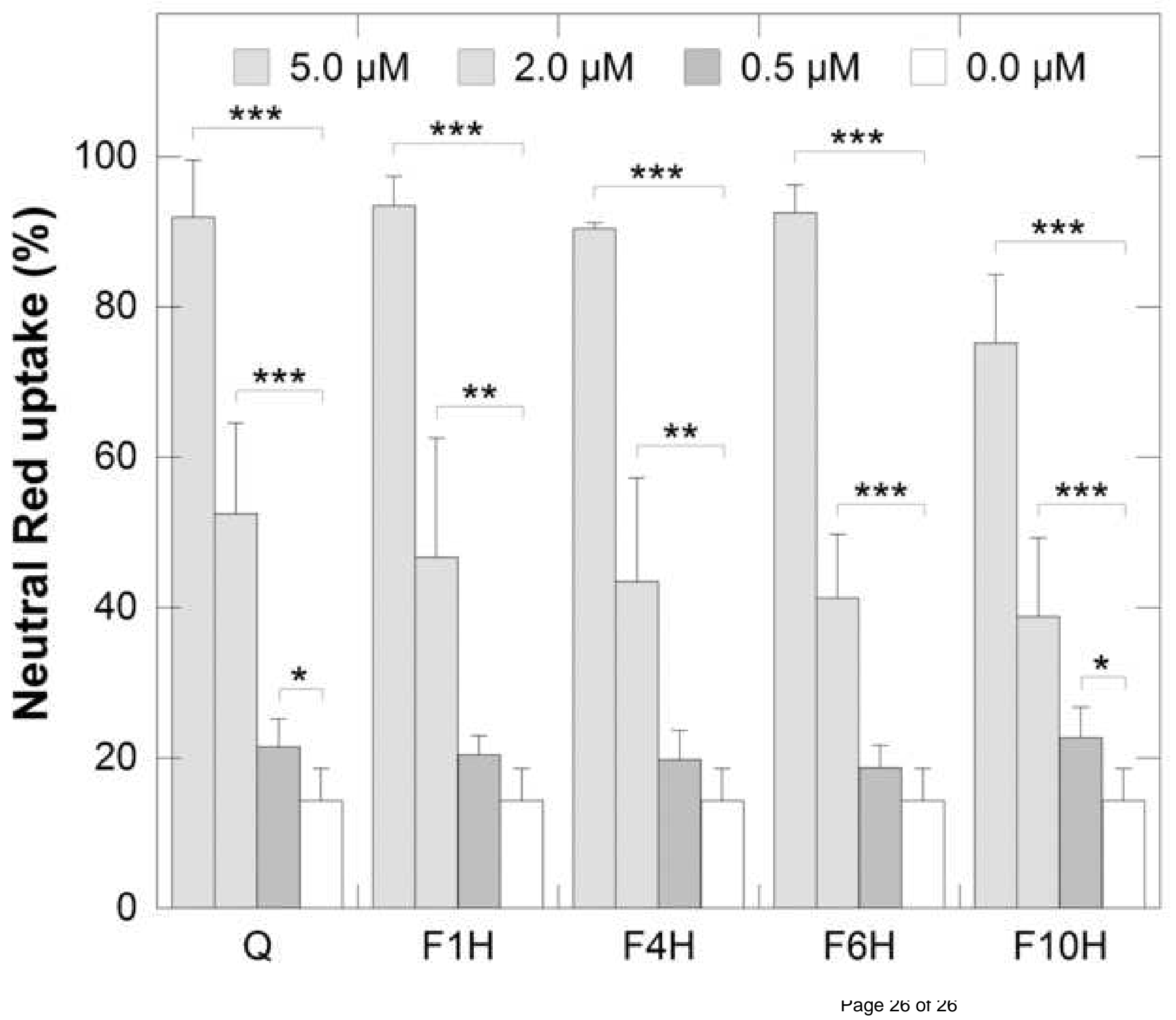

